\title{
O discuRSO da LEgISLAÇÃo SOBRE O SUJEITO dEFICIENTE
}

\author{
THE DISCOURSE OF LEGISLATION ABOUT PERSONS WITH DISABILITY
}

\author{
Reinoldo MARQUEZAN ${ }^{1}$
}

RESU M O : o estudo interroga os efeitos de sentido que são produzidos no discurso da legislação brasileira considerando as estruturas lingüísticas e discursivas nas formas de nomeação do sujeito deficiente. $O$ corpus discursivo retido para análise foi construído a partir das Constituições e das Leis de diretrizes da educação. O dispositivo teórico está filiado à Análise de Discurso de linha francesa iniciada por Michel Pêcheux nos anos 60. A Análise de Discurso trabalha com a concepção de sujeito constituído por um processo de assujeitamento pela língua e pela ideologia e não com o sujeito psicológico. A noção de repetição/ renovação é empregada a nível discursivo porque considera as condições sócio-históricas e ideológicas de produção dos discursos. Os efeitos de sentido dessa noção estão relacionados com o interdiscurso da formação discursiva. A repetição/ renovação se organiza no nível interdiscursivo, mas não se limita ao nível interdiscursivo, pode produzir a renovação discursiva ou retornar ao mesmo. Os discursos que produzem sentidos para/ pelos locutores não são discursos originais, são discursos fundadores replicados. Dessa forma, o sujeito que os pronuncia não é o seu autor e, aquela não é única ou a melhor maneira de pronunciá-los, embora o sujeito tenha essa ilusão. As formulações que nomeiam o sujeito deficienteno discurso legislativo podem produzir tanto o mesmo como o diferente, um eoutro estão relacionados com as condições de produção do discurso, do sentido e do sujeito.

PALAVRAS-CHAVE: sujeito deficiente; efeitos de sentido; repetição/ renovação; legislação; educação especial.

ABSTRACT: the study investigates the sense effects that are produced within the discourse of Brazilian legislation considering linguistic and discursive structures in nomination forms of persons with disability. For the purpose of analysis, the discursive corpus was built from the Brazilian constitutions and from national education laws (Diretrizes da Educação). The theoretical approach is affiliated to the French approach of Discourse Analysis initiated by Michel Pêcheux in the sixties. Discourse Analysis works from the conception that the subject is constituted not as a psychological subject but by submitting to a language process and to ideology. The notion of repetition/ renewal is employed at the discursive level because it considers the ideological and sociohistorical conditions of discourse production. The sense effects of this notion are related to inter-discourse of discursive formation. Repetition/ renewal is organized but not limited to the inter-discursive level; repetition can produce discursive renewal or it can replicate earlier discourse. Discourse that produces sense for/ by enunciators is not original, it replicates founding discourse. Thus, the subject that enunciates such discourse is not the original author and his is not the only or even the best way to enunciate it, even though the subject might have such an illusion. The formulations that nominate the subject with disability in legislative discourse can produce both the same and the different, one and another are related to the conditions of discourse production, of the sense and of the subject.

KEYWORD S: deficient subject; sense effects; repetition/ renewal; legislation; special education.

\footnotetext{
${ }_{1}^{1}$ Professor Doutor do Departamento de Educação Especial. Centro de Educação. Universidade Federal de Santa Maria - reinoldomarquezan@terra.com.br
} 


\section{INTRODUÇÃo}

Este trabalho se propõe a refletir sobre os efeitos de sentido produzidos/ reproduzidos pelas formas de nomeação do sujeito deficiente no discurso da legislação educacional constante das Constituições federais e das Leis de diretrizes da educação (Leis 4.024/ 61, 5.692/ 71 e 9.394/ 96). Efeitos de sentido referem-se aos diferentes sentidos que um mesmo enunciado ou uma mesma palavra pode assumir de acordo com a formação discursiva em que é produzido/ reproduzido. Sujeito deficiente é o sujeito resultante de um processo de assujeitamento pela língua e pela história, ou seja, pela ideologia, e não o sujeito corpóreo. O termo deficiente é tomado para designar as pessoas nomeadas com deficiência, as pessoas portadoras de deficiência eas pessoas com necessidades educacionais especiais. É usado em referência a todas as pessoas que, em diferentes épocas, foram consideradas incapazes ou com capacidades limitadas, de natureza permanente ou transitória, por razões físicas, cognitivas, sensoriais, vocacionais, políticas e/ ou econômicas para o exercício pleno da cidadania.

Esta reflexão está filiada à Análise de Discurso iniciada por Michel Pêcheux, nos anos sessenta na França, e ampliada no Brasil nos anos oitenta a partir dos trabalhos de Eni Orlandi. Trabalho com a noção de repetição/ renovação, para refletir sobre os efeitos de sentido presentes e possíveis nas diferentes manei ras de nomear o sujeito deficientenos discursos das Constituições e das Leis complementares da educação.

Para o percurso de análise dos efeitos de sentido de repetição/ renovação, paráfrase/ polissemia, nas formas de nomear o sujeito deficiente val home de al guns conceitos da A nálise de Discurso. Serão relevantes para este estudo as noções de lei, de arquivo, as concepções de língua, de discurso, de ideologia, de sentido e sujeito, bem como uma breve caracterização sobre a própria A nálise de Discurso.

No trabalho de configuração do corpus considerei o discurso como parte de um processo discursivo aberto que tem relação com o discurso anterior e aponta para outro do qual se pode recortar e analisar diferentes momentos. $\mathrm{O}$ recorte, que representa um momento do processo discursivo, leva em conta fatos da linguagem com a memória. Desse modo, a constituição do corpus já é um trabalho de análise, pois implica decidir em relação às propriedades discursivas a serem consideradas.

O corpus é composto por materiais de arquivo. $\mathrm{O}$ arquivo é tomado como um documento aberto a uma leitura interpretativa considerando a materialidade da língua e a memória no discurso. É esta relação da língua com a história que torna a leitura do arquivo importante para o analista de discurso. 


\section{D ISPOSITIVo e PROCEDimentos de ANÁlise}

A Análise de Discurso é uma disciplina de entremeio (ORLANDI, 2001) e se exerce em espaços habitados simultaneamente. Ela adota, para a sua configuração epistemológica, contribuições do Materialismo Histórico, especialmente a Teoria da Ideologia desenvolvida por Althusser; da Lingüística, no deslocamento da noção de fala para discurso; da Teoria do Discurso como teoria da determinação histórica dos processos semânticos e, também, toma da Psicanálise as noções de inconsciente e de decentramento do sujeito.

Como foi enunciado por Pêcheux (1997a) na epistemologia da A nálise de Discurso, o discurso materializado na linguagem possibilita a produção/ reprodução de sentidos entre os sujeitos. Ao produzir sentidos entre os sujeitos, o discurso está produzindo os próprios sujeitos. Produzindo e etiquetando os sujeitos. Cada um, o operário, o branco, o deficiente, o índio, é interpelado pela evidência da constatação quevincula edissimula a norma identificadora. A análise do funcionamento da língua, enquanto materialidade dos discursos, possibilita compreender os efeitos de sentido constituídos sobre o sujeito deficiente.

Entre os conceitos trabalhados pela teoria discursiva, necessária para esse estudo, está a idéia de lei. Lei é um preceito formulado pela autoridade constituída que se torna norma geral obrigatória imposta coercitivamente à obediência geral. A escrituração da lei é constituída de seqüências discursivas com aparência de um texto neutro e com a finalidade de promover a ordem e o desenvolvimento. A lei, ao funcionar como um discurso, carrega a marca da incompletude que é constitutiva da linguagem e do sujeito. Sendo discurso, ela realiza a inscrição histórico-ideológica das posições-sujeitos, isto é, demarca um território de onde o sujeito vai/ pode significar. Na perspectiva da Análise de Discurso, a lei é um gênero discursivo (GREGOLIN, 2005) do tipo autoritário (ORLANDI, 2003), que se caracteriza por uma relação impositiva entre o enunciador e o enunciatário.

A lei acompanha o desenvolvimento das relações entre os membros da sociedade. N ela reside uma dimensão do processo deluta social protagonizada pelos segmentos organizados da sociedade de modo que nela possam inscreverse. O fato de estar na lei não é garantia de cumprimento pelo Estado. Entretanto, para que um direito possa vir a ser assegurado, énecessário que ele esteja inscrito na lei (CURY, 2005). A condição para que uma norma jurídica seja válida é que ela seja originada em uma autoridade com poder para criá-la. O legislador é investido pela norma fundamental do poder legítimo para criar a lei (BOBBIO, 1995). 
O arquivo não é dado a priori e seu funcionamento é opaco. Guilhaumou e Maldidier (1997, p.164) consideraram a complexidade do fato arquivista e entenderam que 0 arquivo

[...] não é o reflexo passivo de uma realidade institucional, ele é, dentro de sua materialidade e diversidade, ordenado por sua abrangência social. 0 arquivo não é um simples documento no qual se encontram referências; ele permite uma leitura que traz à tona dispositivo e configurações significantes.

$\mathrm{O}$ arquivo não é simplesmente um documento de onde se retiram os referentes, mas aberto a uma leitura interpretativa. Para que dessa leitura faça emergir o "dispositivo e configurações significantes" é necessário considerar a materialidade da língua e a memória no discurso do arquivo. Pêcheux (1997b), diz que a relação entre língua como sistema sintático passível de movimento, e a discursividade como inscrição de efeitos lingüísticos materiais na história constituem a questão principal do trabalho de leitura do arquivo.

A língua constitui a materialidade do discurso que é produto social histórico resultante do trabalho com a linguagem. Para a A nálise de Discurso a falta, as fal has e o equívoco são constitutivos das relações de sentido e de sujeito, o simbólico é aberto e a língua é fluida (ORLANDI, 2002). Assim, a língua não pode dizer tudo e algumas de suas manifestações são falhas. Dessa forma, a regularidade do sistema da língua é afetada e caracterizando o equívoco. Por isso, no âmbito da A nálise de Discurso, a língua é reconhecida pela sua opacidade e não transparência e o equívoco como fato estrutural constitutivo (PÊCHEUX, 2002). A língua está sujeita ao equívoco e a ideologia está sujeita a fal has, essa incompletude produz um movimento constante de renovação dos sentidos, dos sujeitos e dos discursos. Dessa forma, os sentidos, os sujeitos eos discursos sempre podem ser outros. Isso depende de como são afetados pela língua e pela história.

A noção de sentido, compreendida como um efeito de sentidos entre interlocutores (Pêcheux, 1990), é integrante da noção de discurso. O sentido é constituído no contexto. Assim, não há um sentido hierarquicamente mais importante do que os outros sentidos. Todos os sentidos são possíveis e, "em certas condições de produção, há de fato dominância de um sentido sem por isso perder a relação com os outros (implícitos)", diz Orlandi, (1996 p. 20-1). Afirma ainda a autora que a sedimentação dos processos de significação se realiza historicamente, institucional izando um sentido dominante. A institucionalização dá legitimidade e o sentido legitimado torna-se sentido oficial, literal. A literalidade, assim, é produzida historicamente por um efeito de sentido, não existe a priori. "A unidade não preexiste ao emprego" (ORLANDI, 1996, p. 21).

O sentido não está fixado à palavra, "nem tampouco podeser qualquer um: há uma determinação histórica"(ORLANDI, 1996, p. 27). O contexto 
histórico-social é parte constitutiva do sentido. Para a Análise de Discurso, os sentidos são historicamente determinados e o sentido dominante é constituído na formação discursiva que está em relação com uma formação ideológica, a qual o sujeito autor e o sujeito leitor estão assujeitados.

O discurso não é a língua, nem a fala, nem o texto, mas necessita dos elementos lingüísticos para ter existência material. Discurso é efeito de sentido entre locutores. É uma prática social que tem como materialidade uma linguagem e uma regularidade que só pode ser apreendida a partir da análise dos processos de sua produção. O discurso implica uma exterioridade à língua e se encontra no social. Ele é, assim, o lugar onde se articulam os processos ideológicos com os fenômenos lingüísticos e, dessa forma, os processos sócio-históricos são constitutivos dos sentidos.

A ideologia, na perspectiva da A nál ise de Discurso não é um conjunto de valores, ela é tomada como constituinte do sentido e do sujeito. O sujeito não podenão significar, não fazer significar. Ele, frentea um objeto simbólico, élevado a dizer o que este significa: "há assim injunção à interpretação" (ORLANDI, 2001, p.22). A ideologia realiza um apagamento da materialidade da linguagem e produz um sentido (e um sujeito). O sujeito vai, ao mesmo tempo, constituindo a língua e se constituindo por ela. Desta maneira, sujeito e senti do são, ao mesmo tempo, produtores e produtos da linguagem. Assim, ao significar o sujeito se significa e é o seu gesto de interpretação quem decide sobre a constituição do sentido.

A Análise de Discurso trabal ha com o lingüístico e com o ideológico no processo de produção/ interpretação do sujeito e do sentido que o significam e que ele significa. N essa perspectiva, o sujeito não é um indivíduo corpóreo, é um lugar de significação ideologicamente constituído, uma posição-sujeito, isto é, um sujeito que se materializa no entrecruzamento de diferentes discursos e se manifesta no texto pela relação a uma formação discursiva (PÊCHEUX, 1997a). Orlandi (2004, p. 49) de forma semelhante, diz:

Esse sujeito que se define como posição é um sujeito que se produz entre diferentes discursos, numa relação regrada com a memória do dizer (o interdiscurso), definindo-seem função deuma formação discursiva na relação com as demais.

O funcionamento da linguagem se realiza na tensão produzida pelos processos parafrásticos, em que algo do dizer permanece, e os processos polissêmicos, em que há deslocamento de significações. A paráfrase representa, assim, a memória, o retorno ao espaço do dizer, o retorno ao mesmo. A polissemia realiza uma ruptura com o dizer anterior, joga com o equívoco, com o 
esquecimento, produz o diferente. A repetição se movimenta entre o mesmo e o diferente, entre a paráfrase e a polissemia, num espaço que Orlandi (2002) considera tensionado pelas relações de poder. Desse modo, sempre que falamos "deficiente", os sentidos que se constituíram ao longo do tempo retornam, mas podem produzir novos sentidos por efeito das condições de produção.

A noção de repetição/ renovação é empregada no nível discursivo porque considera as suas condições sócio-históricas e ideológicas de produção. Assim, os efeitos de sentido da noção de repetição/ renovação estão relacionados com o interdiscurso da formação discursiva, ou seja, com o conjunto de saberes com os quais a repetição está vinculada. As formações discursivas têm, no seu interior, diferentes discursos, que são o interdiscurso. O entrelaçamento dos diferentes discursos, vindos de diferentes momentos da história, de diferentes lugares sociais, de diferentes autores, caracteriza uma interdiscursividade. Uma formação discursiva apresenta el ementos vindos de outras formações discursivas que podem ser complementares, contraditórios ou excludentes. A formação de um discurso resulta da combinação de diferentes discursos. Assim, conforme Pêcheux (1990, p. 314), uma formação discursiva “[...] não é um espaço estrutural mente fechado, pois é constitutivamente 'invadido' por elementos que vêm de outro lugar (...) que se repetem nela, fornecendo-Ihe suas evidências discursivas fundamentais".

No interior de uma formação discursiva, por não ser ela um espaço fechado, encontram-se elementos que existiram em outros lugares sociais, em outros momentos históricos que, sob novas condições de produção, reconfiguramse e possibilitam outros efeitos de sentidos. Conforme Achard (1999, p. 11), "a estruturação do discursivo vai constituir a materialidade de uma certa memória social". A crescenta o autor que a memória que os discursos exprimem é reconstruída na enunciação. "A enunciação, então, deve ser tomada não como advinda do locutor, mas como operações que regulam o encargo, quer dizer a retomada e a circulação do discurso" (ACHARD, 1999, p. 17). A estruturação do texto, desta forma, é uma questão social; os sentidos são produzidos na/ pela circulação social seguindo uma diferenciação das memórias. Os discursos, assim, contêm uma memória coletiva, na qual os sujeitos de diferentes grupos culturais estão inscritos.

A memória discursiva, para Pêcheux (1999, p. 50), deve ser entendida não como a memória enquanto função psicológica individual, “[...] mas nos sentidos entrecruzados da memória mítica, da memória social inscrita em práticas, e da memória construída do historiador". Pêcheux (1999, p. 52) considera a memória como estruturação da material idade discursiva entendida como dialética da repetição e da regularização de tal forma que

[...] a memória discursiva seria aquilo que, em face de um texto que surge como acontecimento a ler vem restabelecer os 'implícitos' (quer dizer, mais tecnicamente, os pré-construídos, elementos citados e relatados, discursos-transversos, etc.) de que sua leitura necessita: a condição do legível em relação ao próprio legível. 
A repetição se organiza no nível interdiscursivo e assim, não se limitando ao nível intradiscursivo, pode produzir a renovação ou o retorno. A noção de repetição formulada por Deleuze (2006) considera que o retorno do mesmo, pel o fato de reaparecer em outro lugar e em outro tempo, deixa de ser o mesmo e passa a ser outro.

O corpus discursivo retido para essa análise foi constituído a partir das Constituições, das Leis de Diretrizes e Bases da Educação Nacional e da Lei de Diretrizes e Bases do Ensino de 1ํㅡ 2o Graus. É um corpus de arquivo. O corpus é constituído por seqüências discursivas (sd) e estruturado segundo um plano definido tendo como referencia as condições de produção do discurso. Para a A nálise de Discurso, o corpus não é dado a priori. É construído por gestos de leitura, de interpretação e de compreensão de seu próprio objeto de investigação. O processo, portanto, não segue critérios empíricos e sim critérios teóricos (ORLANDI, 2002). No trabalho de configuração do corpus, há que se considerar o discurso como parte de um processo discursivo aberto que tem relação com o discurso anterior eaponta para outro do qual se pode recortar eanalisar diferentes momentos. Desse modo, a constituição do corpus já é um trabalho de análise, pois implica decidir em relação às propriedades discursivas a serem consi deradas.

As decisões do processamento metodológico em A nálise de Discurso não são adotadas em uma perspectiva modelar ou de rotinização sistêmica (SANTOS, 2004). Elas são tomadas ao longo do estudo, no processo recorrente de ir e vir do corpus à teoria, tendo em vista as características de movência, opacidade e alteridade, assumidas pelos discursos.

\section{Resultados e discussões}

Passemos, então, à análise do funcionamento da repetição/ renovação da nomeação do sujeito deficiente nos discursos da legislação conforme o corpus constituído para esse estudo. Nas Constituições de 1824, 1891, 1934 e 1937 o sujeito deficiente, embora pressuposto, não está nomeado no texto legislativo. Nessa análise trabal ho com o sujeito deficiente nomeado e não com o sujeito deficiente pressuposto, por isso começo com a Constituição de 1946.

Sd1: Constituição dos Estados Unidos do Brasil, 1946.

Art. 172. Cada sistema de ensino terá obrigatoriamente serviços de assistência educacional que assegurem aos alunos necessitados condições de eficiência escolar.

A designação genérica de "alunos necessitados", por uma análise enunciativa, indica diferentes sentidos de sujeito. Entre esses sentidos o de sujeito deficiente. Não há, nesse momento, intenção de dar visibilidade a um sentido. 
MARQUEZAN, R.

Isso, no entanto, não quer dizer que o sujeito deficiente não signifique e não tenha um lugar para de lá significar.

Sd2: Lei de Diretrizes e Bases da Educação Nacional, Lei n. 4.024/ 61.

Art. 88. A educação de excepcionais deve, no que for possível, enquadrar-se no sistema geral de educação, a fim de integrá-los na comunidade.

Art. 89. Toda iniciativa privada considerada eficiente pelos Consel hos Estaduais de Educação, e relativa à educação de excepcionais, receberá dos poderes públicos tratamento especial mediante bolsas de estudo, empréstimos e subvenções.

O sujeito deficienteénomeado nessa Lei como "excepcional". O gesto de nomeação (PÊCHEUX, 1990) dá visibilidade a um sentido e produz um efeito de acréscimo. O enunciado "educação de excepcionais" está inscrito numa formação discursiva constituída por uma conjuntura política e ideológica de legitimação moral, social e humanização da educação, e aponta para a direção de um sujeito, o sujeito deficiente. A expressão ganha o sentido nesta formação discursiva em que é produzida, é aí que o indivíduo é interpelado em sujeito do discurso. O lugar, portanto, da construção do sentido e da constituição do sujeito é a formação discursiva. Na formação discursiva, admite Pêcheux (1997a), o sentido ganha unidade e o sujeito adquire identidade. É a formação discursiva que regula o que o sujeito pode e deve dizer, o que o sujeito não pode e não deve dizer numa determinada relação social, funcionando como lugar de articulação entre língua e discurso.

Sd3: Constituição da República Federativa do Brasil, 1967.

Art. 169. [...]

§ 2 - - Cada sistema de ensino terá, obrigatoriamente, serviços de assistência educacional que assegurem aos alunos necessitados condições de eficiência escolar.

Constituição da República Federativa do Brasil, 1969.

Art. 175. [...]

$\S 4$ - Lei especial disporá sobre a assistência à maternidade, à infância e à adolescência e sobre a educação de excepcionais.

Art. 177. [...]

§ 20 - Cada sistema de ensino terá, obrigatoriamente, serviços de assistência educacional, que assegurem aos alunos necessitados condições de eficiência escolar. 
"Alunos necessitados", trazido pela Constituição de 1946, Art. 172, volta a ser a nomeação adotada pelas Constituições de 1967 e 1969. "Excepcional", apresentado pela Lei n. 4.024/61, também volta no enunciado que nomeia o sujeito deficiente na Carta de 1969. A repetição da mesma nomeação indica, nesses dois casos, a ausência da participação da sociedade civil e da comunidade científica no processo de elaboração da Lei, pois já era corrente o uso de outra nomenclatura. É um dizer parafrástico que retorna aos mesmos espaços do dizer, isto é, diferentes formulações do mesmo dizer. Este dizer parafrástico em que os enunciados se repetem deforma literal epor paráfrase, não rompe com a memória instituída e retém os movimentos dos sentidos e dos sujeitos deficientes.

Esse gesto de nomeação politicamente determinado significa que mesmo ao trocar de nome o sujeito não deixa de significar. O jogo com palavras vindas de formações discursivas distintas e com diferentes historicidades faz aparecer o político e o histórico na língua. Assim, o sujeito deficiente nomeado "necessitado", "excepcional", não deixa de existir, de produzir sentido. A renomeação continua a produzir sentido.

Sd4: Lei de Diretrizes e Bases para o Ensino de 1o e 2o Graus, Lei n. 5.692/ 71.

Art. 9o. Os al unos que apresentem deficiências físicas ou mentais, os que se encontrem em atraso considerável quanto à idade regular de matrícula e os superdotados deverão receber tratamento especial, de acordo com as normas fixadas pelos competentes Conselhos Estaduais.

Nesse processo histórico de constituição do sujeito deficiente pelo discurso da legislação, o enunciado da Lei n. 5.692/ 71 "Os alunos queapresentem deficiências físicas ou mentais [...] e os superdotados [...]" realiza um desdobramento da identificação genérica. Com esse desdobramento na nomeação do sujeito deficiente, a legislação realiza um isolamento que permite a comparação, a avaliação e, com isto, a classificação dos sujeitos (HAROCHE, 1992). O trabalho de classificação revela o desejo de conhecer o outro, de tornálo transparente, previsível e que não possa representar surpresa e ameaça.

Do ponto de vista da anál ise discursiva do silêncio, a ação de classificar o outro realiza um movimento de quebrar com o silêncio e ali fixar, encher o lugar de sentidos. A fixação de sentidos dá a ilusão de que o dizer limita a profusão de sentidos, ao passo que o silêncio pode gerar muitos sentidos (ORLANDI, 1993).

A classificação representa também uma tentativa de não negar o outro e sim de fazê-lo conhecido; um procedimento de demarcação de suas características de identidade e de suas diferenças para torná-lo interpretável e passível de dominação. Fazer o sujeito pertencer a uma classe permite estabelecer diferenças entre os sujeitos que tem o mesmo pertencimento e aqueles que não 
MARQUEZAN, R.

têm. Essa diferenciação se baseia no reforçamento das semelhanças entre os componentes de um mesmo grupo enas diferenças com/ entremembros degrupos diferentes.

A classificação justifica e hierarquiza as diferenças com o outro deficiente. As diferenças se tornam a materialidade de classificação a partir do memento em que o sujeito deficiente é constituído como "um objeto de estudo, uma área para desenvolvimento, um campo de ação" (GRIGOLETTO, 2002, p. 82). Assim, na medida em que se o coloca numa escala de classes que expressa seu grau de desempenho e de desenvolvimento biológico, psicológico e social ese indica as atividades que poderá e deverá fazer, onde, quando e quem fazêlas, se constrói uma discursividade que sobredetermina os sentidos eo sujeito deficiente.

Sd5: Constituição da República Federativa do Brasil, 1988.

Art. 203. [...]

IV. A habilitação e reabilitação das pessoas portadoras de deficiência e a promoção de sua integração à vida comunitária;

V. A garantia de um salário mínimo de benefício mensal à pessoa portadora de deficiência e ao idoso que comprovem não possuir meios de prover à própria manutenção ou de têla provida por sua família, conforme dispuser a lei.

Art. 208. [...]

III. A tendimento educacional especializado aos portadores de deficiência, preferencialmente na rede regular de ensino;

A nomeação do sujeito deficiente como "pessoa portadora de deficiência" é realizada pela Constituição de 1988. Ela consagra uma nomeação corrente na época: "portador de deficiência" ou simplesmente "deficiente". A associação do substantivo pessoa ao adjunto adnominal portadora de deficiência destaca o propósito de o texto constitucional tentar marcar o caráter humano e digno do sujeito deficiente. Há nessa nomeação, considerando as condições de produção, uma movimentação do sentido e do sujeito deficiente. Esta movimentação ocorre, de acordo com Guimarães (1996), porque existe alguma enunciação anterior que dá condições para que o nome exista, pois não há como enunciar senão dentro do contexto histórico. A designação, para o autor, ao se instituir "instala como lugar de estabilidade referencial um sentido pelo apagamento de outros. A política do sentido está, assim, na língua, a partir da constituição de sentidos da enunciação" (GUIMARÃES, 2005, p. 75).

Ao referir o sujeito deficiente como a pessoa, parece haver o desejo de incluí-lo no espaço da cidadania como capaz de um comportamento "decente e ordeiro" (OLIVEIRA, 2002, p. 46). E, com essa designação, produzir um 
apagamento do sentido que o desqualifica como incapacitado para o exercício dos direitos e deveres. Isso foi possível, porque as condições de produção da Carta Constitucional se fizeram em clima de abertura, ou seja, num momento histórico da afirmação da cidadania que permitiu alargar as conquistas sociais. Essa tentativa de inclusão que a palavra pessoa carrega no discurso da Constituição de 1988 esbarra no termo seguinte da designação: "portadora”. A pal avra portador se vincula à linguagem médica, na sua acepção sanitarista e tem o sentido de portar ou conduzir, trazer consigo ou em si; que hospeda e transmite al go nocivo; que pode contagiar. Com esse efeito de sentido, a designação "portadora" atualiza uma memória associada à doença, à dor, ao sofrimento, à rejeição, à morte. Em "portadora de deficiência", a designação "deficiência" é tomada pelo sentido de portadora, ou seja, de contagiosa. Dessa forma, o discurso legal conduz/ mantém a rejeição/ exclusão do sujeito deficiente na/ pela sociedade.

Sd6: Lei de Diretrizes e Bases da Educação Nacional, Lei n. 9.394/ 96.

Art. 4․ [...].

III. Atendimento educacional especializado gratuito aos educandos com necessidades especiais, preferencialmente na rede regular de ensino;

A rt. 58. Entende-se por educação especial, para efeitos desta Lei, a modal idade de educação escolar, oferecida preferencialmente na rede regular de ensino, para educandos portadores de necessidade especiais.

Art. 59. Os sistemas de ensino assegurarão aos educandos com necessidades especiais:

Na Lei n. 9.394/ 96 o sujeito deficiente é nomeado como "educandos com necessidades especiais", aparecendo também “educandos portadores de necessidades especiais". Essa nomeação tem origem no Relatório Warnock (1978), em que a designação "necessidades educativas especiais" apareceu pela primeira vez e na designação "portador de necessidades especiais" usada na Conferência de Salamanca (1994). No enunciado a palavra "educando" remete, apropriadamente, o atendimento educacional do sujeito deficiente para a esfera da educação. O "com", na designação "educandos com necessidades especiais", assume a condição da falta constitutiva do sujeito deficiente e que é inerente à deficiência. O retorno de "portadores" faz aparecer uma não-coincidência do dizer a não existência de um só sentido do discurso (AUTHIER-REVUZ, 1998). Reinscreve o mesmo na ordem do discurso. Uma repetição da ordem de uma "memória cheia, saturada", (COURTINE, 1999, p. 21), reconhecimento de que os enunciados fazem parte da mesma formação discursiva.

Nas Constituições de 1946, 1967 e 1969, o sujeito deficiente é nomeado pela mesma formulação: "alunos necessitados". O fato, no entanto, de ser uma formulação que repetea mesma estrutura lingüística, não constitui o mesmo efeito 
de sentido e de sujeito. O sentido de "alunos necessitados" de 46 é diferente do sentido de "alunos necessitados" de 67 e 69, caracteriza uma repetição do nível interdiscursivo, já que mudam as condições de produção. O efeito de sentido é influenciado pela forma como necessidade se inscreve nos contextos históricos e ideológicos de 46 e 67/ 69. A mesma formulação repetida em 67 e 69 caracteriza uma repetição do nível intradiscursivo, pois as condições de produção são muito semelhantes e o sentido tende a se repetir.

A Constituição de 1969 repete a formulação de 1946: "alunos necessitados". Repete também a formulação "educação de excepcionais", da LDBEN de 1961. N esse caso, a estrutura lingüística da formulação legislativa de 1969 é outra, mas sugere um efeito de sentido que se repete. Parece haver uma relação parafrástica de sentido e ambas as formulações referem o ensi no do sujeito deficiente.

N as nomeações realizadas pela Constituição de 1988, “pessoa portadora de deficiência", e pela LDBEN n. 9.394/ 96, "educandos com/ portadores de necessidades especiais", não há repetição das mesmas estruturas lingüísticas. Contudo, ambas as formulações encaminham para uma repetição de sentido, ou seja, ambas referem à falta, à ausência, o especial e, assim, não ultrapassa a fronteira da formação discursiva do discurso médico. A não repetição da estrutura lingüística parece, nesse caso, não assegurar a mudança de sentido de falta por espaço, de ausência por possibilidade, de especial por atendimento pedagógico.

\section{D ISCUSSÕES E CONSIDERAÇÕES FINAIS}

Para analisar a repetição/ renovação no discurso sobre o sujeito deficiente produzido pela legislação educacional brasileira a partir das seqüências discursivas do corpus constituído, demanda ultrapassar o nível lingüístico e referilos ao conjunto de discursos possíveis tendo presente as suas condições de produção.

Os discursos se repetem. N ós os repetimos sem nos darmos conta que el es são da ordem do já-dito. Sendo assim, são as próprias repetições que fazem os discursos. Então, a repetição éconstitutiva do discurso. A memória éconsiderada por Orlandi (2001) como o saber discursivo, a memória do dizer. É o que foi dito e o que é dito a respeito de um assunto, mas que, com o passar do tempo, esquecemos como foi dito, por quem e em que circunstância fica como um já-dito, sobre o qual os nossos sentidos se produzem.

As formulações designatórias de sujeito deficiente, remetidas para análisenos seus contextos lingüístico-ideológicos de produção, repetem e renovam sentidos. A designação "alunos necessitados" impõe-lhe uma interdição do seu 
dizer que tenta se efetivar na discursividade do especial: atendimento especial, pessoa especial, educação especial. Isso implica numa ruptura unilateral da rel ação que exclui, não havendo reconhecimento do interlocutor como sujeito legítimo da relação.

A formulação "Cada sistema de ensino terá obrigatoriamente serviços de assistência educacional que assegurem aos alunos necessitados condições de eficiência escolar" (CONSTITUIÇÃ O DOS ESTADOS UNIDOS DO BRASIL, 1946, artigo 172) identifica, classifica e orienta/ determina as atividades a que o sujeito deficiente será submetido. É um discurso feito sobre o sujeito deficiente, que ocupa e preenche o espaço em que ele significa. Fala do lugar do sujeito deficiente, fala pel o efala sobre ele. Fal a como o representante do sujei to deficiente legitimado pela verdade da ciência e pela autoridade da lei.

Pêcheux (1997a) focaliza sua discussão sobre a ideologia no vínculo existente entre a construção do sentido e a constituição do sujeito, na figura da interpelação: fala-se do/ sobre o sujeito, fala-se para o sujeito antes que ele fale. Assim, éa coletividade, como entidade pré-existente, queimpõea marca ideológica sobre cada sujeito.

A designação "alunos necessitados" volta ser a nomeação adotada pelas Constituições de 1967 e 1969. “Excepcional”, apresentado pela Lei n. 4.024/ 61, também volta no enunciado que nomeia o sujeito deficiente na Carta de 1969. Exata repetição, como vimos, é um dizer parafrástico que retorna aos mesmos espaços do dizer. Esse dizer parafrástico, em que os enunciados se repetem de forma literal e por paráfrase, não rompe com a memória instituída e retém os movimentos dos sentidos e dos sujeitos deficientes.

O enunciado da Lei n. 5.692/ 71 "Os alunos que apresentem deficiências físicas ou mentais [...] e os superdotados [...]" realiza um desdobramento da identificação genérica de sujeito deficiente que permite a comparação, a avaliação e, com isso, a classificação dos sujeitos. A classificação consente conhecer o outro, torná-lo transparente e previsível.

A nomeação do sujeito deficiente como "pessoa portadora de deficiência" consagra as nomeações correntes na época: "portador de deficiência" e "deficiente". A nomeação ao referir o sujeito deficiente como a pessoa parece querer incluí-lo no espaço da cidadania e produzir um apagamento do sentido que o desqualifica para o exercício dos direitos e deveres. Ao referir o sujeito deficiente como "pessoa" querendo incluí-lo no espaço de cidadania, produz um apagamento de sentido e o desqualifica como sujeito com direitos e deveres. Esse sentido de inclusão vinculado à palavra "pessoa" no discurso da Constituição se choca com a designação "portadora". A designação "deficiência" em "pessoa portadora de deficiência" é tomada pelo sentido de contagiosa, de doença. Assim, o discurso legal repete a exclusão do sujeito deficiente na/ pela sociedade. 
A Lei n. 9.394/ 96 nomeia o sujeito deficiente como "educandos com necessidades especiais" e também como "educandos portadores de necessi dades especiais". No enunciado, a palavra "educando" , como interpretamos, remete ao atendimento educacional do sujeito deficiente para a esfera da educação. $O$ "com", em "educandos com necessidades especiais", assume a condição da falta constitutiva inerente ao sujeito deficiente. O retorno de "portadores" reinscreve o mesmo na ordem do discurso favorecendo o reconhecimento de que os enunciados pertencem à mesma formação discursiva.

As seqüências discursivas tomadas para análise transparecem uma sobreposição de discursos político, médico, psicológico, pedagógico, significando e subjetivando o sujeito deficiente de distintas maneiras. Assim, "alunos necessitados", "excepcionais", "pessoas portadoras de deficiência”, "educandos com necessidades especiais" se substituem em posição parafrástica, significando a deficiência que, por sua vez, significa o sujeito deficiente. A sobreposição dos enunciados, no entanto, não iguala os sentidos de alunos necessitados, de excepcionais, de pessoa portadora de deficiência, nem educandos com necessidades especiais. Há, nesses casos, deslizamentos metafóricos, renovações, decorrentes das condições de produção desses discursos que os tornam outros.

"Aluno necessitado" surge e se reforça nas políticas assistencialistas e intervencionistas do Estado sobre a cidadania. A designação "excepcional" mostra a presença do discurso da medicina na construção do sentido e na constituição do sujeito deficiente. "Pessoa portadora de deficiência" e "educando com necessidades especiais" transparecem a rel ação simbiótica do discurso médico com o psicológico e com o pedagógico sobre o sujeito deficiente que se constitui no/ pelo entrecruzamento desses discursos. A posição de sujeito do discurso, a posição de sujeito deficiente, provém, conforme Pêcheux (1997a), da exterioridade, do interdiscurso que o constitui.

A análise das formulações que nomeiam o sujeito deficiente no discurso da legislação em apreço revela uma polissemia contida, uma construção parafrástica. Isso quer dizer que se for considerada a repetição apenas no nível intradiscursivo, nas mesmas condições de produção, teremos a repetição do mesmo, mas se considerada a repetição no nível interdiscursivo, em outras condições de produção, a repetição apontará para o diferente. A produção do mesmo e do diferente está diretamente relacionada com as condições de produção de sentido, de sujeito e de discurso.

\section{ReferênCIAS}

ACHARD, P. M emória eprodução discursiva do sentido. In: ACHARD, P. et al. Papel da memória. Tradução José H orta Nunes. Campinas: Pontes, 1999. p. 11-22. 
AUTHIER-REVUZ, J. Palavras incertas: as não coincidências do dizer. Tradução deOrlandi, E. Campinas: UNICAMP, 1998.

BOBBIO, N. Teoria do ordenamento jurídico. Tradução Maria Cel este Leite Santos. Brasília: UnB, 1995.

CURY, C.R.J. O s fora de série na escola. Campinas: Armazém do I pê (A utores Associados), 2005.

COURTINE, J-J. O chapéu deClementis: observações sobrea memória eo esquecimento na enunciação do discurso político. Tradução de Rodrigues, M.R. In: INDURSKY, F.; FERREIRA, C.L. (Org.). O s múltiplos territórios da A nál ise deD iscurso. Porto A legre: Sagra Luzzatto, 1999. p. 15-22.

DELEUZE, G. D iferença e repetição. Tradução de Orlandi, L. e Machado R. Rio de Janeiro: Graal, 2006.

GREGOLIN, M .R.V. N as mal has da mídia: agenciando os gêneros, produzindo sentidos. In: BA RON AS, R. L. (Org.). I dentidade, cultura elinguagem. Campinas: Pontes, 2005. p. 23-34.

GRIGOLETTO, M. A resistência das palavras: discurso e colonização britânica na Índia. Campinas: UNICAMP, 2002.

GUILHAUMOU, J.; MALDIDIER, D. Efeitos do arquivo: a análise do discurso no lado da história. In: ORLANDI, E. (Org.). Gestos de leitura: da história no discurso. Campinas: UNICAMP, 1997. p. 163-18.

GUIMARÃES, E. O s sentidos decidadão no I mpério ena República do Brasil. In: GUIMARÃES, E.; ORLANDI, E. (Org.). Língua e Cidadania: o português no Brasil. Campinas: Pontes, 1996. p. 39-46.

. O s limites do sentido: um estudo histórico e enunciativo da linguagem. Campinas: Pontes, 2005.

HAROCHE, C. F azer dizer, querer dizer. Tradução deOrlandi, E. São Paulo: Hucitec, 1992.

OLIVEIRA, I.B. A prendizagens culturais cotidianas, cidadania e educação. In: OLIVEIRA, I.B.; SGA RBI, P. (Org.). Redes culturais, diversidade educação. Rio deJaneiro: DP\&A, 2002. p. 37-56.

ORLANDI, E. As formas do silêncio: no movimento dos sentidos. Campinas: UNICAMP, 1993. . D iscurso e texto: formação e circulação dos sentidos. Campinas: Pontes, 2001. . A nálise de D iscurso: princípios e procedimentos. 4. ed. Campinas: Pontes, 2002. . A linguagem eseu funcionamento: as formas do discurso. Campinas: Pontes, 2003. . Inter pretação: autoria, leitura e efeitos do trabal ho simbólico. Campinas: Pontes, 2004. . D iscurso e Leitura. Campinas: UNICAMP, 1996.

PÊCHEUX, M. A nál ise automática do discurso (A A D -69). In: GADET, F.; HAK, T. Por uma análise automática do discurso: uma introdução à obra de Michel Pêcheux. Tradução deMariani, B. Campinas: UNICAMP, 1990. p. 61-161. 
MARQUEZAN, $R$.

PÊCHEUX, M. Semântica eD iscurso: uma crítica a afirmação do óbvio. Tradução deOrlandi, E. Campinas: Editora da UNICMP, 1997a.

. Ler o arquivo hoje. In: ORLANDI, E. (Org.). Gestos de leitura: da história no discurso. Tradução Mariani, B. et al. Campinas: UN ICAMP, 1997b. p. 55-66.

2002. . Discurso: estrutura ou acontecimento. Tradução de Orlandi, E. Campinas: Pontes,

SANTOS, J. B.C. U ma reflexão metodológica sobre análise de discursos. In: FERN ANDES, C.A.; SA NTOS, J.B.C. A nálise do discurso: unidadee Dispersão. U berlândia: Entre Meios, 2004. p. 109-118.

Recebido em 26/ 05/ 2008

Reformulado em 14/ 11/ 2008

Aprovado em 04/ 12/ 2008 